DOI: https://doi.org/10.15688/lc.jvolsu.2018.3.14

UDC 347.78

LBC 67.404.3

\title{
THE LEGAL NATURE OF RELATIONS ARISING AMONG CO-OWNERS OF THE EXCLUSIVE COPYRIGHT
}

\author{
Elizaveta Yu. Martyanova \\ Perm State National Research University, Perm, Russian Federation
}

\begin{abstract}
Introduction: the problem of identifying the nature of the legal relationship arising among persons jointly possessing the exclusive copyright is considered. In order to establish the type of legal connection among the coowners of the exclusive copyright, such methods of scientific knowledge as analysis, synthesis, analogy, the system-structural and dogmatic-legal methods are used. Results: it is proved that the criterion of dividing legal relations into absolute and relative ones should be recognized as the nature of the interaction of the right holder with other persons, given that the force of the subjective right is due and predetermined by its content. It is established that the joint owners of the exclusive copyright have both unidirectional and multidirectional interests. It is revealed that the settlement of different-vector interests characterizes the internal side of the interaction of the co-owners of the right. Conclusions: the author concludes that the relations arising among the co-owners of the exclusive copyright are relative, organizational in nature and are aimed at coordinating the interaction and coordination of the multi-vector will of the persons jointly possessing the exclusive copyright, in order to determine the legal fate of the right.
\end{abstract}

Key words: joint ownership, exclusive copyright, legal relations.

Citation. Martyanova E.Yu. The Legal Nature of Relations Arising among Co-Owners of the Exclusive Copyright. Legal Concept, 2018, vol. 17, no. 3, pp. 102-107. DOI: https://doi.org/10.15688/lc.jvolsu.2018.3.14

УДК 347.78

ББК 67.404 .3

\section{ПРАВОВАЯ ПРИРОДА ОТНОШЕНИЙ, ВОЗНИКАЮЩИХ МЕЖДУ СООБЛАДАТЕЛЯМИ ИСКЛЮЧИТЕЛЬНОГО АВТОРСКОГО ПРАВА}

\author{
Елизавета Юрьевна Мартьянова \\ Пермский государственный национальный исследовательский университет, \\ г. Пермь, Российская Федерация
}

Введение: рассматривается проблема выявления характера правоотношения, возникающего между лицами, совместно обладающими исключительным авторским правом. С целью установления типа правовой связи между сообладателями исключительного авторского права используются такие методы научного познания, как анализ, синтез, аналогия, системно-структурный и догматико-юридический. Результаты: обосновано, что критерием деления правоотношений на абсолютные и относительные следует признать характер взаимодействия правообладателя с иными лицами, учитывая, что действие субъективного ○ं права обусловлено и предопределено его содержанием. Установлено наличие у совместных обладателей исключительного авторского права как однонаправленных, так и разнонаправленных интересов. Выявлено, что урегулирование разновекторных интересов характеризует внутреннюю сторону взаимодействия сообладателей права. Выводы: автором сделан вывод, что отношения, возникающие между сообладателями исключительного авторского права, носят относительный, организационный характер и направлены на ключительным авторским правом, с целью определения юридической судьбы права. 
Ключевые слова: совместное правообладание, исключительное авторское право, правоотношения.

Цитирование. Мартьянова Е. Ю. Правовая природа отношений, возникающих между сообладателями исключительного авторского права // Legal Concept = Правовая парадигма. - 2018. - Т. 17, № 3. - C. 102-107. DOI: https://doi.org/10.15688/lc.jvolsu.2018.3.14

\section{Введение}

Разделение субъективных гражданских прав и правоотношений на классификационные единицы является одной из узловых тем исследований и дискуссий в юридической литературе. Классификационная система относительных и абсолютных правоотношений многими теоретиками и цивилистами рассматривается в качестве основной дихотомии правоотношений, имеющей ключевое практическое значение $[17$, с. 83]. В доктрине отмечается ряд изъянов в проработке критериев данной классификации, в количестве и содержательном наполнении ее единиц и прочее. В качестве особо острой проблемы выделяется отсутствие единого критерия деления абсолютных и относительных правоотношений и субъективных прав. Разрешение вопроса о критерии деления прав и правоотношений на относительные и абсолютные имеет значение, в том числе, при определении природы взаимоотношений сообладателей субъективного права. Так, несмотря на то, что природе исключительного авторского права традиционно присваивается характер абсолютности [3, c. 169], неразрешенной остается проблема характера правоотношения, возникающего между лицами, совместно обладающими одним исключительным авторским правом.

\section{Основные подходы к критерию демаркации относительных и абсолютных правоотношений}

По мнению В.К. Райхера, основное различие между абсолютными и относительными правоотношениями кроется в характере действия соответствующих прав относительно третьих лиц: действие относительных прав является опосредованным, «отраженным» [12, с. 199]. С.С. Алексеев высказывает позицию, согласно которой абсолютный характер правоотношения, в отличие от относительного, предполагает наличие неопределенного кру- га субъектов, которые «обязаны воздерживаться от нарушения данного конкретного субъективного права» $[1$, с. 106]. Аналогичной точки зрения придерживается В.К. Андреев, полагая, что абсолют состоит в праве носителя субъективного права потребовать «от любых третьих лиц воздержаться от вторжения в правовую сферу» правообладателя [2, c. 14]. С.А. Синицын, напротив, утверждает, что критерием деления прав на абсолютные и относительные является «специфика содержания и цели правового регулирования», а не число обязанных и управомоченных лиц [16, c. 18]. Представляется возможным отметить, что переосмысление традиционных подходов и позиционирование какого-либо установленного признака как истинно ключевого и образующего ядро изучаемой классификации в некоторых случаях может означать формулирование концепции качественно новой классификации. В доводах, приведенных С.А. Синицыным, усматривается не только предложение иного критерия классификации, но и подбор соответствующего новому критерию содержательного наполнения понятия абсолютного и относительного права, неизменным остается лишь наименование классификационных единиц. Думается, что при данных условиях необходимо свидетельствовать появление классификации, отличной от дихотомии относительных и абсолютных прав.

В целях разграничения абсолютных и относительных правоотношений ряд исследователей предлагает обращать внимание на право, которое лежит в основе правоотношения. В научных трудах освещена позиция, согласно которой абсолютные правоотношения имеют в своей основе абсолютное право, которому приписывают характер неизменности, естественности, надгосударственности [7, c. 165]. Н.М. Коркунов, характеризуя абсолютные права, указывает на то, что эти права имеют силу «против всех и каждого» [9, с. 150], в противовес относительным, ограниченным правам. По мысли Д.Н. Бахраха, сущность абсолютных прав проявляется при их осуще- 
ствлении в том, что у всех лиц возникает обязанность «не препятствовать или даже содействовать этому» [4, с. 6]. Необходимо отметить, что в различных правовых концепциях понятие абсолютных прав имеет различное смысловое наполнение. Так, Л.Д. Воеводин полагал концепцию абсолютных прав несостоятельной в виду невозможности ее применения ко всем видам прав, например, к конституционным [6, с. 104]. Абсолютные права в конституционно-правовом смысле характеризуются как неотчуждаемые [7, с. 165], при этом имущественные права, в том числе вещные, исключительные авторские права данным признаком не обладают. Концепция абсолютных правоотношений нередко трактуется в преломлении именно к вещным правам. Так, О. Гирке отмечал, что абсолютный характер проявляется в господстве над вещью, в наличии «неопределенного числа лиц, обязанных уважать это господство» [5, с. 60], именовал право собственности неограниченным правом [22, с. 363].

В многообразии теоретических подходов к определению признака, позволяющего разграничить относительные и абсолютные права, усматривается общее начало: ключевое отличие сводится к характеру взаимодействия правообладателя с иными лицами. Даже при определении содержания права как критерия данной классификации [15, с. 88], представляется невозможным отрицать, что действие субъективного права обусловлено и предопределено его содержанием. Содержание субъективного права неизбежно проявляется в его действии, при осуществлении права, которое не мыслится в правовом вакууме, в отсутствие динамики отношений.

\section{Определение характера правоотношений, возникающих между сообладателями субъективного гражданского права}

Рассмотрение вопроса о характере правоотношений, возникающих между сообладателями субъективного гражданского права, в преломлении дихотомии абсолютных и относительных правоотношений, осложняется не только неразрешенностью ряда проблем теоретического конструирования самой классификации, но и особенностями отдельных ви- дов субъективных гражданских прав, которые становятся объектом рассуждений теоретиков и цивилистов.

В доктрине присутствуют попытки разрешения указанного вопроса применительно к институту множественности лиц в субъективном гражданском праве безотносительно дифференциации прав на отдельные виды, что свидетельствует о признании некоторыми авторами необходимости формулирования и закрепления общих положений о множественности лиц, охватывающих все подотрасли гражданского права. К.А. Сердюков отмечает, что множественность лиц характеризуется взаимостеснением гражданских прав и обязанностей сообладателей субъективного права [14, c. 13,22$]$. Данное утверждение связано с наличием у совместных обладателей права как однонаправленных, так и разнонаправленных интересов. Однонаправленный интерес имеет место при совершении совместных действий по определению юридической судьбы субъективного права или его объекта, то есть таких действий, которые «лица вынуждены совершать при использовании общего ресурса, находящегося в режиме коммунальной собственности» [10]. Разнонаправленный интерес проявляется при определении порядка осуществления субъективного права между сообладателями, например, при распределении доходов от использования объекта, находящегося в совместном обладании.

В юридической литературе отношения сообладателей субъективного права исследуются, как правило, применительно к отдельным видам субъективных прав. Так, рассуждая о характере взаимоотношений сособственников, многие авторы склоняются к тому, что права сособственников проявляют относительный характер при взаимодействии между собой относительно вещи, а абсолютный - при их взаимодействии с третьими лицами [18, с. 387-388]. Противником данной точки зрения выступает С.А. Синицын, отмечая, что отношения сособственников носят только абсолютный характер, так как порождаются правом собственности, абсолютным по своей природе, и не существуют вне его. Определение характера отношений сообладателей, по мысли ученого, возможно только при осуществлении права, но так как 
ни один из них не может его осуществлять в полном объеме самостоятельно, то речь должна идти не о правах, а только о правомочиях, характер которых не может отличаться от абсолютного права собственности [15, с. 114]. Схожую позицию занимает К.Б. Ярошенко, отмечая, что отношения сособственников «построены по типу абсолютных правоотношений», а обязательства из соглашения, заключаемого между ними, существуют вне вещного правоотношения [11, с. 579]. При этом большая часть исследователей приходят к выводу о наличии относительных правоотношений между сообладателями права собственности. Так, О.А. Халабуденко усматривает в правоотношениях сособственников относительный характер, не отрицая их вещно-правовоую природу [19, с. 48]. Идея о неизбежности присутствия относительного элемента в вещной конструкции общей собственности поддерживается и другими исследователями [13, с. 94]. Характер отношений между сокредиторами (содолжниками) в научной литературе определяется как относительный $[8$, с. 16] и, как правило, не вызывает дискуссий.

При изучении исключительных авторских прав, Е.И. Харитонова отмечает, что имущественные интеллектуальные права, могут быть как абсолютными, так и обязательственными: из рассуждений автора следует, что абсолютный характер проявляется при взаимодействии объект - правообладатель, а обязательственный - при распоряжении правами [20, с. 227-228]. В данных рассуждениях очевидно смешение двух самостоятельных классификаций и противопоставление их элементов друг другу. По мысли И.Е. Якубивского, при распоряжении таким правом обязательственный характер приобретает не само исключительное право, а появляющееся правоотношение по его отчуждению, предоставлению и так далее [21, с. 4].

\section{Выводы}

Исходя из того, что правоотношение по совместному обладанию исключительным авторским правом возникает только между определенными в ст. 1229 ГК РФ субъектами сообладателями исключительного авторско- го права, и допустить нарушение прав или не выполнить обязанность, являющуюся содержанием указанного правоотношения, может только сообладатель права, а не какое-либо иное лицо, представляется возможным признать относительный характер данных правоотношений. Кроме того, указанные отношения носят организационный, управленческий характер, так как направлены на координирование взаимодействия и согласования разновекторной воли конкретных лиц, с целью формирования общей воли и определения юридической судьбы исключительного авторского права, что предопределяет содержательное наполнение прав и обязанностей сообладателей, характер взаимодействия с иными лицами.

\section{СПИСОК ЛИТЕРАТУРЫ}

1. Алексеев, С. С. Общая теория права: в 2 т. / С. С. Алексеев. - М. : Юрид. лит., 1981. - Т. 2. $360 \mathrm{c}$.

2. Андреев, В. К. Право собственности в России / В. К. Андреев. - М. : БЕК, 1993. - 144 с.

3. Аутлева, Ф. Т. Исключительные права как ключевая юридическая конструкция прав на результаты интеллектуальной деятельности / Ф. Т. Аутлева // Пробелы в российском законодательстве. 2008. - № 2.- С. 169-171.

4. Бахрах, Д. Н. Индивидуальные субъекты административного права / Д. Н. Бахрах // Государство и право. - 1994. - № 3. - С. 16-24.

5. Васьковский, Е. В. Учебник гражданского права / Е. В. Васьковский. - СПб. : Изд-во юрид. кн. магазина Н. К. Мартынова, 1896. - 188 с.

6. Воеводин, Л. Д. Конституционные права и обязанности советских граждан / Л. Д. Воеводин. М. : Изд-во Моск. ун-та, 1972. -300 с.

7. Гасанов, К. К. Абсолютные права человека и ограничения прав / К. К. Гасанов, А. В. Стремоухов // Правоведение. - 2004. - № 1 (252). - С. 164-173.

8. Ермолаев, С. Н. Множественность лиц в гражданском праве : дис. ... канд. юрид. наук : 12.00.03 / Ермолаев Серафим Николаевич. - Краснодар, 2014. - $186 \mathrm{c}$.

9. Коркунов, Н. М. Лекции по общей теории права / Н. М. Коркунов. - СПб. : Изд-во юрид. кн. магазина Н. К. Мартынова, 1909. - 364 с.

10. Остром, Э. Управляя общим. Эволюция институтов коллективной деятельности / Э. Остром. - Электрон. текстовые дан. - Режим доступа: https://istina.net.ua/vlogenia/elinor\%20ostrom.pdf(дата обращения: 27.01.2018). - Загл. с экрана. 
11. Право собственности: актуальные проблемы/ отв. ред. В. Н. Литовкин, Е. А. Суханов, В. В. Чубаров. - М. : Статут, 2008. $-731 \mathrm{c}$.

12. Райхер, В. К. Абсолютные и относительные права (к проблеме деления хозяйственных прав) / В. К. Райхер // Вестник гражданского права. Научный журнал. - 2007. - Т. 7, № 2. - С. 144-204.

13. Рыженков, А. Я. Общая долевая собственность на имущество хозяйственных товариществ и обществ / А. Я. Рыженков, А. Е. Черноморец, С. А. Чаркин // Пробелы в российском законодательстве. -2010 . - № 2. - С. 90-95.

14. Сердюков, К. А. Правоотношения с множественностью лиц в российском гражданском праве : автореф. дис. ... канд. юрид. наук : 12.00 .03 / Сердюков Константин Анатольевич. - Ростов н/Д, 2011. $-26 \mathrm{c}$.

15. Синицын, С. А. Абсолютные и относительные субъективные права. Общее учение и проблемы теории гражданского права. Сравнительно-правовое исследование / С. А. Синицын. - М. : Юриспруденция, 2015. - 568 с.

16. Синицын, С. А. Общее учение об абсолютных и относительных субъективных гражданских правах : автореф. дис. ... д-ра юрид. наук : 12.00 .03 / Синицын Сергей Андреевич. - М., 2017. - 604 с.

17. Ушницкий, Р. Р. Об абсолютной природе корпоративного правоотношения / Р. Р. Ушницкий // Евразийский юридический журнал. - 2011. № 8 (39). - C. 83-89.

18. Филатова, У. Б. Институт права общей собственности в странах романо-германской правовой семьи (Германии, Австрии, Швейцарии, Франции и России: сравнительно-правовое исследование) : дис. ... д-ра юрид. наук : 12.00 .03 / Филатова Ульяна Борисовна. - М., 2015. - 437 c.

19. Халабуденко, О. А. Имущественные права. Кн. 1. Вещное право / О. А. Халабуденко. - Кишинев : Междунар. независимый ун-т Молдовы, 2011. $-305 \mathrm{c}$.

20. Харитонова, О. И. Правоотношения интеллектуальной собственности, которые возникают вследствие создания результата творческой деятельности : моногр. / О. И. Харитонова. - Одесса : Феникс, 2011. - $346 \mathrm{c.}$

21. Якубивский, И. Е. Абсолютный характер имущественных прав интеллектуальной собственности / И. Е. Якубивский // Наука. Общество. Государство : электрон. науч. журн. - 2013. - № 3. - Электрон.текстовые дан. - Режим доступа: http://esj.pnzgu.ru/files/ esj.pnzgu.ru/yakubivsky_ie_13_3_20.pdf(дата обращения: 23.01.2017). - Загл. с экрана.

22. Gierke, O. Deutsches Privatrecht/O. Gierke. Electronic text data. - Mode of access: http://dlibpr.mpier.mpg.de/m/kleioc (date of access: 19.12.2017). Title from screen.

\section{REFERENCES}

1. Alekseev S.S. Obshchaya teoriya prava: $v 2 t$. T. 2 [General Theory of Law. In 2 vols. Vol. 2]. Moscow, Yurid. lit. Publ., 1981.360 p.

2. Andreev V.K. Pravo sobstvennosti v rossii [Ownership in Russia]. Moscow, Bek Publ.,, 1993. 144 p.

3. Autleva F.T. Isklyuchitelnye prava kak klyuchevaya yuridicheskaya konstruktsiya prav na rezultaty intellektualnoy deyatelnosti [Exclusive Rights as a Key Legal Construction of the Rights to the Results of Intellectual Activity]. Probely $v$ rossiyskom zakonodatelstve, 2008, no. 2, pp. 169-171.

4. Bakhrakh D.N. Individualnye subyekty administrativnogo prava [Individual Subjects of Administrative Law]. Gosudarstvo i pravo, 1994, no. 3, pp. 16-24.

5. Vaskovskiy E.V. Uchebnik grazhdanskogo prava [Textbook of Civil Law]. Saint Petersburg, 1896. $188 \mathrm{p}$.

6. Voevodin L.D. Konstitutsionnye prava $i$ obyazannosti sovetskikh grazhdan [Constitutional Rights and Duties of Soviet Citizens]. Moscow, 1972. $300 \mathrm{p}$.

7. Gasanov K.K., Stremoukhov A.V. Absolyutnye prava cheloveka i ogranicheniya prav [Absolute Human Rights and Restrictions of Rights]. Pravovedenie, 2004, no. 1 (252), pp. 164-173.

8. Ermolaev S.N. Mnozhestvennost lits $v$ grazhdanskom prave: dis. ... kand. yurid. nauk [Multiplicity of Persons in the Civil Law. Cand. jurid. sci. diss.]. Krasnodar, 2014. 186 p.

9. Korkunov N.M. Lektsii po obshchey teorii prava [Lectures on the General Theory of Law]. Saint Petersburg, 1909. $364 \mathrm{p}$.

10. Ostrom E. Upravlyaya obshchim. Evolyutsiya institutov kollektivnoy deyatelnosti [Managing the General. Evolution of Collective Institutions]. 2010. URL: https://istina.net.ua/vlogenia/elinor\%20ostrom. pdf (accessed 27 January 2013).

11. Litovkin V.N., Sukhanov E.A., Chubarov V.V., eds. Pravo sobstvennosti: aktualnye problemy [Ownership: Current Problems]. Moscow, Statut Publ., $2008.731 \mathrm{p}$.

12. Raykher V.K. Absolyutnye i otnositelnye prava ( $\mathrm{k}$ probleme deleniya khozyaystvennykh prav) [Absolute and Relative Rights (to the Problem of Dividing Economic Rights)]. Vestnik grazhdanskogo prava. Nauchnyy zhurnal, 2007, vol. 7 , no. 2, pp. 144-204.

13. Ryzhenkov A.Ya., Chernomorets A.E., Charkin S.A. Obshchaya dolevaya sobstvennost na imushchestvo khozyaystvennykh tovarishchestv i obshchestv [Common Share Ownership of Property of Business Partnerships and Companies]. Probely $v$ rossiyskom zakonodatelstve, 2010, no. 2, pp. 90-95. 
14. Serdyukov K.A. Pravootnosheniya $s$ mnozhestvennostyu lits $v$ rossiyskom grazhdanskomprave: avtoref. dis. ... kand. yurid. nauk [Legal Relations with the Plurality of Persons in the Russian Civil Law. Cand. jurid. sci. abs. diss.]. Rostov-on-Don, 2011.26 p.

15. Sinitsyn S.A. Absolyutnye $i$ otnositelnye subyektivnye prava. Obshchee uchenie i problemy teorii grazhdanskogo prava. Sravnitelno-pravovoe issledovanie [Absolute and Relative Subjective Rights. General Doctrine and Problems of the Theory of Civil Law. Comparative Legal Research]. Moscow, Yurisprudentsiya Publ., 2015. 568 p.

16. Sinitsyn S.A. Obshchee uchenie ob absolyutnykh $i$ otnositelnykh subyektivnykh grazhdanskikh pravakh: avtoref. dis. ... d-ra yurid. nauk [The General Doctrine of Absolute and Relative Subjective Civil Rights. Dr. jurid. sci. abs. diss.]. Moscow, 2017. $604 \mathrm{p}$.

17. Ushnitskiy R.R. Ob absolyutnoy prirode korporativnogo pravootnosheniya [On the Absolute Nature of the Corporate Legal Relationship]. Evraziyskiy yuridicheskiy zhurnal, 2011, no. 8 (39), pp. 83-89.

18. Filatova U.B. Institut prava obshchey sobstvennosti $v$ stranakh romano-germanskoy pravovoy semyi (Germanii, Avstrii, Shveytsarii, Frantsii i Rossii: sravnitelno-pravovoe issledovanie): dis. ... d-ra yurid. nauk [The Institute of Common Property Law in the Countries of the Romano-German Legal Family (Germany, Austria, Switzerland, France and Russia: Comparative Legal Research). Dr. jurid. sci. diss.]. Moscow, 2015. 437 p.

19. Khalabudenko O.A. Imushchestvennye prava. Kniga 1. Veshchnoe pravo [Property Rights. Book 1. Property Law]. Kishinev, Mezhdunar. nezavisimyy unt Moldovy, 2011.305 p.

20. Kharitonova O.I. Pravootnosheniya intellektualnoy sobstvennosti, kotorye voznikayut vsledstvie sozdaniya rezultata tvorcheskoy deyatelnosti [Legal Relations of Intellectual Property that Arise as a Result of Creative Activity]. Odessa, Feniks Publ., 2011.346 p.

21. Yakubivskiy I.E. Absolyutnyy kharakter imushchestvennykh prav intellektualnoy sobstvennosti [Absolute Nature of Property Rights of Intellectual Property]. Nauka. Obshchestvo. Gosudarstvo, 2013, no. 3. URL: http://esj.pnzgu.ru/ files/esj.pnzgu.ru/yakubivsky_ie_13_3_20.pdf (accessed 23 January 2017).

22. GierkeO. Deutsches Privatrecht. URL: http://dlibpr.mpier.mpg.de/m/kleioc (accessed 19 December 2017).

\section{Information about the Author}

Elizaveta Yu. Martyanova, Postgraduate Student, Department of Civil Law, Perm State National Research University, Bukireva St., 15, 614990 Perm, Russian Federation, lizaveta.fomina@mail.ru.

\section{Информация об авторе}

Елизавета Юрьевна Мартьянова, аспирант кафедры гражданского права, Пермский государственный национальный исследовательский университет, ул. Букирева, 15, 614990 г. Пермь, Российская Федерация, lizaveta.fomina@mail.ru. 